\title{
GCU
}

Glasgow Caledonian

University

University for the Common Good

\section{Reducing driver distraction by utilizing augmented reality head-up display system for} rear passengers

Wang, S.; Charissis, V.; Lagoo, R.; Campbell, J.; Harrison, D.K.

Published in:

2019 IEEE International Conference on Consumer Electronics (ICCE)

DOI:

10.1109/ICCE.2019.8661927

Publication date:

2019

Document Version

Author accepted manuscript

Link to publication in ResearchOnline

Citation for published version (Harvard):

Wang, S, Charissis, V, Lagoo, R, Campbell, J \& Harrison, DK 2019, Reducing driver distraction by utilizing augmented reality head-up display system for rear passengers. in 2019 IEEE International Conference on Consumer Electronics (ICCE). IEEE, IEEE ICCE - International Conference in Consumer Electronics 2019, Las Vegas, United States, 11/01/19. https://doi.org/10.1109/ICCE.2019.8661927

\section{General rights}

Copyright and moral rights for the publications made accessible in the public portal are retained by the authors and/or other copyright owners and it is a condition of accessing publications that users recognise and abide by the legal requirements associated with these rights.

Take down policy

If you believe that this document breaches copyright please view our takedown policy at https://edshare.gcu.ac.uk/id/eprint/5179 for details of how to contact us. 


\title{
Reducing Driver Distraction by Utilizing Augmented Reality Head-Up Display System for Rear Passengers
}

\author{
S. WANG, V. CHARISSIS, R. LAGOO, J. CAMPBELL, \& D. K. HARRISON \\ Glasgow Caledonian University, Glasgow, UK \\ vassilis.charissis@gcu.ac.uk
}

\begin{abstract}
Long distance travelling and commuting can be particularly tiring for the driver and the rear passengers. The level of driver distraction could be further increased if younger passengers onboard are idle for long time during the drive. This paper presents a novel Augmented Reality (AR) Head-Up Display (HUD) interface that aims to attract rear passengers' attention through assortment of infotainment applications superimposed on the side car-windows. The system additionally offers a bespoke provision of educational value, which provides superimposed data and games available for the different landmarks. The simplified interface enables the use from younger passengers and seniors alike. The proposed system has undergone two main evaluations involving 50 users and 10 families aiming to identify the system usability. The evaluation took place in a full-scale Virtual Reality driving simulator, which tested the drivers/parents' ability to avoid collisions. The evaluation outcome offered an informative appraisal of the systems efficiency and overall positive feedback from the users.
\end{abstract}

\section{INTRODUCTION}

Driving is a demanding process that requires the uninterrupted attention of the user for the uneventful completion of this task. The attention seeking activities within a vehicle that could create accident-prone conditions were traditionally linked to the infotainment systems.

Yet passengers could equally affect driver's attention. In particular the younger passengers could instigate a number of attention-demanding situations in which the driver is enticed to check briefly and respond accordingly. This, not only mentally engages the driver to another task, but also on occasion, the driver attempts physically to check the back-seats via the middle mirror or by turning of the head. This brief distraction could result in a collision with hazardous results.

Furthermore, this effect multiplies if the driver is also the parent of the younger passengers. This poses a major concern as current studies indicate that an increasing number of families with dependent children choose to take their children to school by car or to travel long distances with the family [1].

This paper presents an alternative solution that aims to attract younger passengers' attention for long periods of time, provide them with educational information and enable them to interact with the provided infotainment. This solution is based on an Augmented Reality (AR) Head-Up Display (HUD), which operates on the passenger side windows [2, 3]. Notably the AR
HUD technology enhances the user immersion and improves user's reaction time whilst offering positive usability experience $[4,5]$.

The proposed system adopts interface design and methodology from our previous Head-Up Display (HUD) interfaces designed for navigation and collision avoidance purposes $[6,7 \& 8]$. Furthermore, the proposed system evolves from our previous designs and aims to reduce the driver distraction and improve driver's response times and collision avoidance capabilities due to passenger distractions [2, 3].

Overall, the paper is structured as follows: The first section introduces the driver's distraction caused by the passengers. The following section presents the proposed system design requirements, challenges and solutions. The third section presents the evaluation system employed for this user trial and the evaluation results. Finally, the paper concludes with an overall appreciation of the system benefits and drawbacks as well as a future plan of work.

\section{PAssengers' Distraction}

Long-distance car journeys confine the passengers in the small vehicular interior with limited interactivity. Smart-tablets and phones are offering a temporary alternative, which is yet limited by the time passengers can spend on a particular task, and the required wireless connectivity. The attention span of the younger passengers within the vehicle is hardly maintained by these means typically resulting in frustration, which further affects driver's concentration. Furthermore, a large number of younger passengers might experience dizziness and feel unwell if spending significant amount of time looking downwards on a tablet device or book whilst the vehicle is in motion. Notably studies observed that more than half the parents prefer to drive without any children for long distances [9]. In general, short car journeys were found to be more pleasant than long ones [1]. This issue although documented and discussed extensively still hasn't been tackled effectively by current technologies.

To this end, some in-car games have already been designed for short-distance drive situations namely: "Backseat Playground", "nICE" and "Mileys" use special equipment, phones or touchpads to play the games $[9,10,11]$. Similar studies have 
been conducted, by automotive manufacturers, utilizing enhanced versions of their backseat entertainment systems. Some of these prototypes used motion and optical sensor technology to transfer the rear seat window into a gesture touch panel. Yet these attempts were purely experimental and did not offer a more immersive and subtle way of interaction for the users. Furthermore, the particular attempts were designed for new vehicles only and as such the previous car-models could not benefit from consumer electronics installed retrospectively.

\section{SYSTEM DESIGN REQUIREMENTS}

Adhering to previous work, it was evident that employing Head-Up Display technology expands the vehicular controls and interaction to the vast estate of the windshield and vehicle windows without affecting the interior design with the use of additional buttons and screens. The proposed HUD system is projected on the side window and offers a selection of infotainment options that could cover the topics of interest both for younger and older passengers as illustrated on Figure 1 below.

Yet the proposed HUD interface is not merely another projection gimmick for customer enticing purposes. The particular HUD system design employs the Augmented Reality (AR) element, which superimposes information related to the external environment to the gaming story [12]. By blending seamlessly, the two, the gaming software, embedded on the system, could adapt to the external environment landmarks and provide the younger population with informative, yet enjoyable gaming experience $[3,5,6]$.

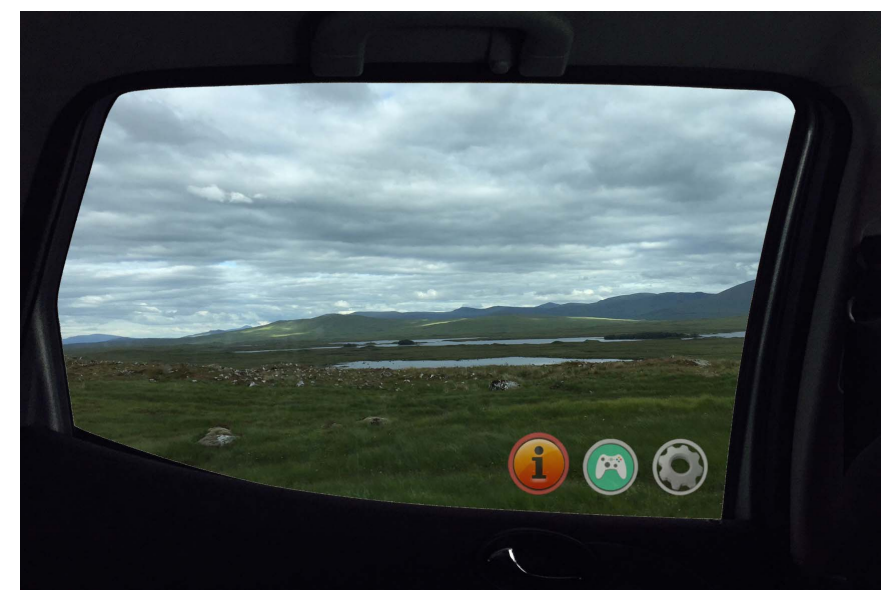

Fig. 1. Screenshot of the first version of the HUD interface activated during the VR Driving Simulator testing.

Furthermore, the AR HUD and GPS tracked route combination, utilises the external route-scenes to provide the gaming experience with the 3D gaming background. The latter design approach reduces the younger passengers' isolation to a completely virtual environment typically provided by the commercially available games. The interface was primarily designed to be operated by Leap Motion hand gestures, which has an optimal space of interaction in near proximity to the Leap Motion sensor. The latter perceives motions in a pyramidal space above the sensor device. As such the early version interface icons were positioned at the lower middle-right side of the windscreen $[5,6]$ as depicted in Figure 1 above.

However, the preliminary evaluation, presented a number of issues that resulted in increased arm fatigue of the users. In order to reduce the fatigue, a typical XBOX controller was employed. Additionally, the interface icons were enlarged and

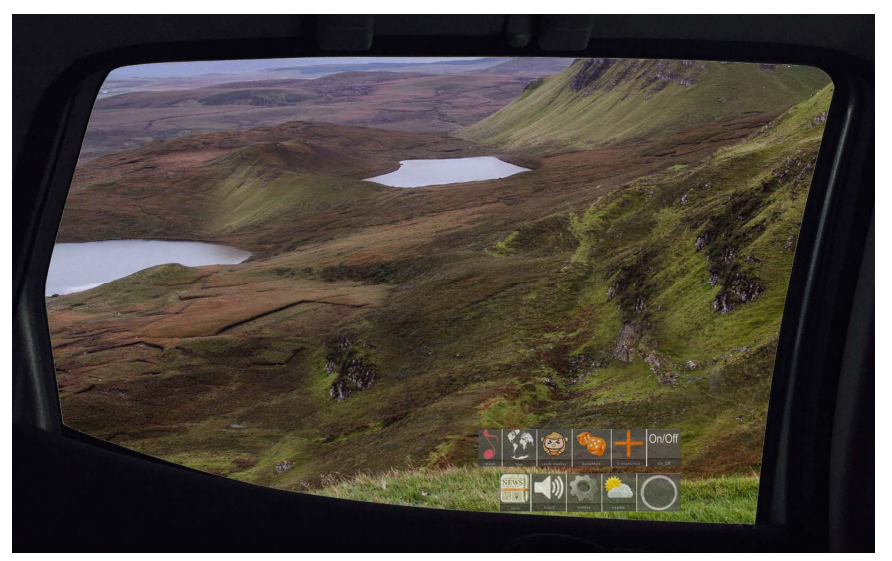

Fig. 2. Screenshot of the new HUD interface in action.

moved on the lower, far-right corner as presented in Figure 2.

In this second interface the lower right corner is easily accessible and visible by the user, which is not constrained by the sensor limitations of the first device (Leap Motion).

The group of users that evaluated both versions unanimously preferred the use of the controller instead of the gesture recognition system due to the complexity of the first interface and the number of movements required to operate the different applications. This could also be attributed to the fact that game controllers have been commercially available for the last four decades whilst gesture recognition systems have not been employed in any major system and application or product.

\section{A. Software Requirements}

The software enables the user to interact with a simplified visual interface developed to be easily accessible and comprehendible by younger users as young as three years old [13]. The main menu comprises three icons, which provide an assortment of different activities such as information, entertainment and settings as depicted in the Figure 3 below. The activation of each main menu icon provides a submenu which offers multiple choices related to the selected category. The system is intentionally designed in two levels so as to minimise time and effort consuming wandering through multiple menus which are typically encountered in most the 
in-vehicle systems. As such the main menu remains uncluttered and requires minimum effort to access any of the provided applications.

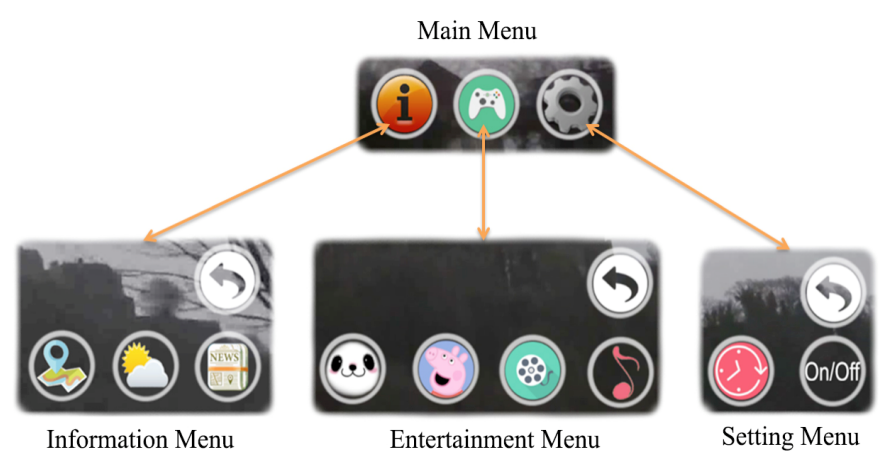

Fig. 3. HUD display interface main menu tree diagram.

The design of the system interface takes into consideration also the variety of users that might access it and particularly the very young users as well as the senior passengers which are easily intimidated and demotivated by complex interfaces. Both groups require simple and efficient interfaces that deliver the context without endeavouring into intricate selection processes.

\section{B. Hardware Requirements}

The system design and development took into consideration that the proposed HUD should be comprised by hardware components that could be incorporated in the confined space of a typical middle-sized vehicle interior. Additionally, the components should be reasonably priced in order to be financially viable as an add-on option for the automotive manufacturers. As such, we opted for off-the-shelf components, at this stage that have proven quality and functionality and they offer a cost-effective option. Yet a fully bespoke system could be devised if deemed necessary.

Additionally, the proposed system aims to offer the option to fit this device retrospectively to older models, enabling the consumer electronics approach. The hardware system consists of a Nano/micro/mini-short throw, HD projector mounted in the ceiling of the vehicle, a polymer combiner applied on the inside of the windows, and a mini custom computing unit which feeds the projector and coordinates the visuals with the vehicle's GPS. The latter could be replaced with occupants' mobile phones if the vehicle doesn't possess a GPS.

A gaming pad/controller (wireless or wired) could be used to manipulate the system. During the laboratory experiments with different types of equipment it was observed that the in-vehicle ceiling-projector was not an obstacle for the driver's main mirror. Yet the projection beam could be an issue with low or no light conditions (i.e. night driving). For this reason, an auto-dimming light sensor is required for the correct regulation of projection brightness.

\section{SimUlation REQUIREMENTS}

\section{A. Evaluation}

The system evaluation was performed in the Virtual Reality Driving Laboratory (VRDS Lab), which is designed explicitly for experimentation with novel vehicular interfaces.

The particular evaluation was devised to take place in two different arms. The first was the evaluation of 50 users -40 parents and 10 children aged 3-10 years old. This part of the experiment was based primarily on a custom for the occasion Technology Acceptance Model, which aimed to, investigate the users' preferences and retrieve their subjective feedback.

The second arm of the simulation involved 10 families with one or two kids, which travelled a 40 minutes distance within the simulated environment whilst different accident scenarios occurred and challenged the driver/parent to avoid. This second experiment contrasted in two different runs the use of the proposed HUD interface for the rear passengers against traditional means used to keep the child occupied during the drive. For this reason, various items (i.e. tablets, toys, and books) were provided to the children on this simulation run.

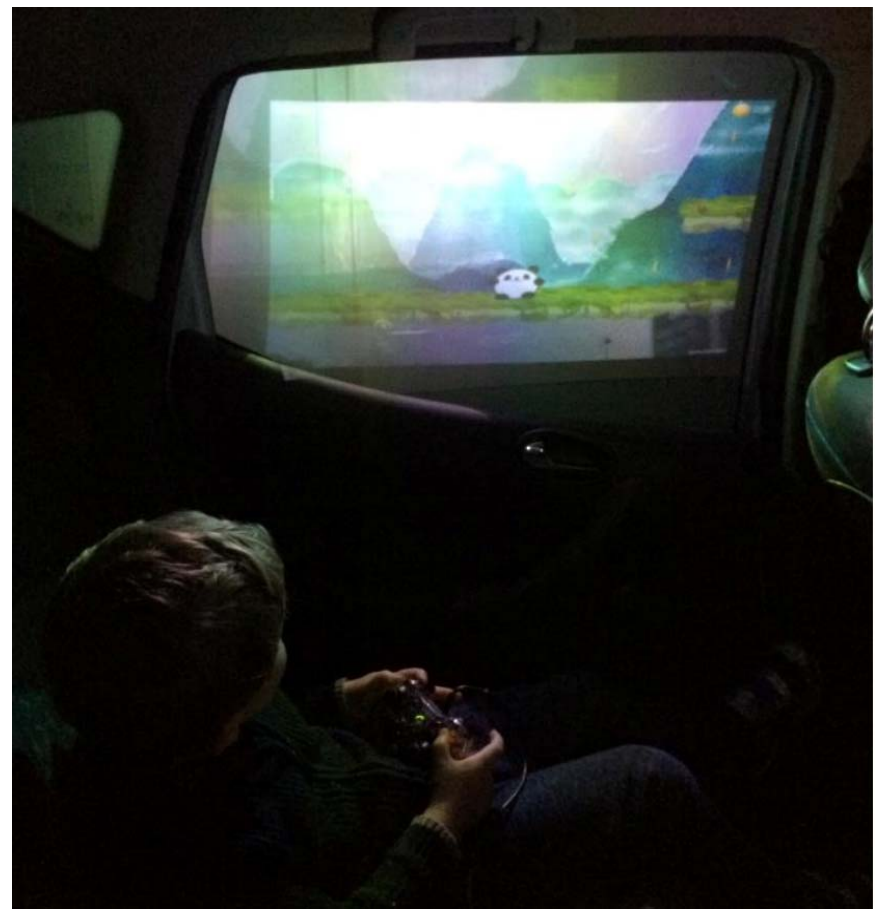

Fig. 4. Young participant on the Family long distance drive evaluation with the use of HUD interface.

The simulation scenario was based on rear-collision accidents provided by the Strathclyde Police department. The accident models were followed with minor customisations maintains a baseline of accident conditions in which we could evaluate standardised accident parameters depending the 
prototype system under trial [1, $2 \& 3]$. The 3D simulated environment is modelled in photorealistic manner on the motorway network extending from Glasgow to Edinburgh and to Sterling in Scotland. This paper will discuss primarily a selection of the first part of the interface evaluation (50 users) and present an indicative appraisal of the drivers' performance of the system evaluation by the families.

\section{B. Participants}

The fist part of the evaluation was performed by 50 users ( 40 parents and 10 children). The second part of the evaluation was carried out by 10 families, which had at least one child in the back seat and the parent/driver held a valid driving licence.

\section{Driving Simulator}

The driving simulator employed for the all the parts of the evaluation of the proposed system is developed in-house and continues the evolution of the bespoke VR driving simulator used on previous system experiments $[2,7,8]$.

This is the fourth generation VR driving simulator which is designed explicitly for the testing of vehicular interfaces that are currently on a prototype level and require a safe and controlled environment for testing during the iterative process. The simulator entails a full-scale Mercedes A-Class vehicle, positioned in a CAVE (Cave Augmented Virtual Environment) room. The CAVE offers a fully immersive, surround projection space produced by multiple HD/3D projectors.

The driver's immersion is further enhanced by the photorealistic environment representing existing routes in Scotland. In addition, a state of the art 5.1 surround audio system replicates faithfully the environment sounds as well as the vehicular sounds. The surround audio feeds into vibrating devices positioned on the vehicle floor replicating the road bumps, potholes and crashing effects during collisions, augmenting further the driving experience. The Artificial Intelligence (AI) for the computer-controlled vehicles has been further improved that are populating the scenes in order to create seamless accident events $[6,7,14]$.

The vehicle interior is fully equipped with dashboard touch-screen and vehicle instrumentation. During each user trial, the driving simulation software records driver's performance and actions (i.e. driver's speed, lane position, distance from the lead vehicle, distance from the neighbouring vehicles, and simulation elapsed time) every 0,03 seconds, maintaining a standardised database through experiments and prototype systems. The above data can provide an assement of the response time in the imminent collision situations and the actual number of collisions occurred.

\section{EVALUATION RESUlts}

The evaluation results for the two different evaluation schemes are presented below. The first evaluation offered an encouraging view towards the acceptance of the particular technology and the way it was embedded in a typical family vehicle as illustrated below in Figure 5.

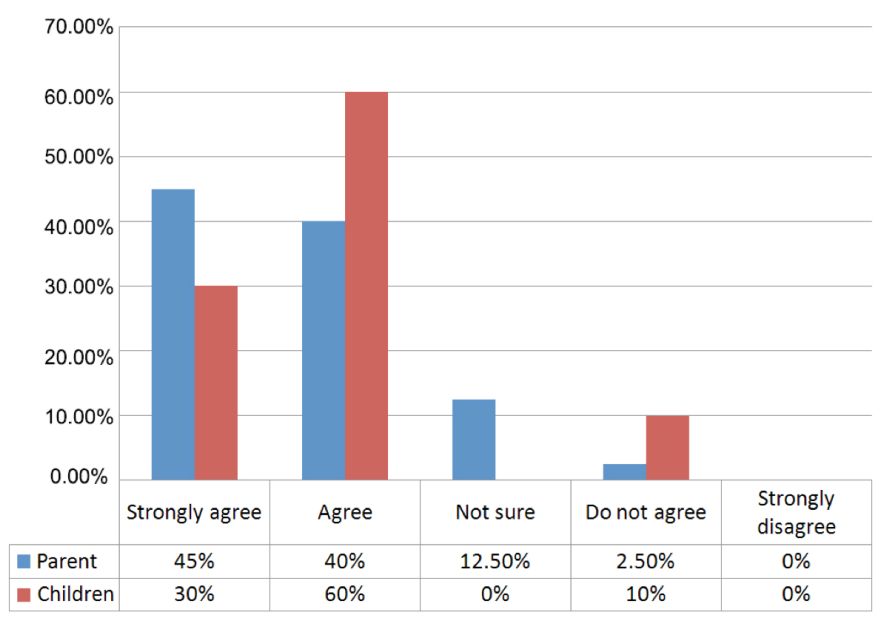

Fig. 5. The system is attractive for everyday use.

The system attractiveness for everyday use achieved an approval (Strongly agree/ agree) of $85 \%$ by the parents and $90 \%$ by the children participants.

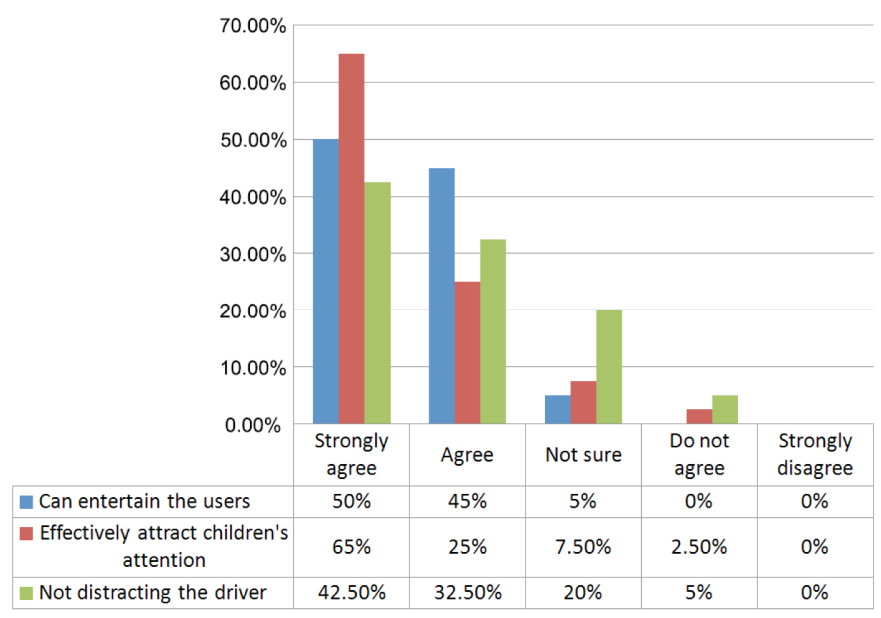

Fig. 6. Parents' feedback for the system's three main attributes.

Specifically, the parent's view was affirmative towards the overall system functionality. In particular $90 \%$ of the parents strongly agree/agree that the system can effectively attract the children's attention. Additionally, $95 \%$ are positive that the system can entertain the users (of any age) whilst $75 \%$ found the system non-distracting for the driver. On the latter question $20 \%$ of the users were indecisive with regards to the non-distracting ability of the system towards the driver. 
For this reason, the second part of the evaluation was designed to investigate further the actual benefits and drawbacks of the system, on long run driving conditions with the use of the VR driving simulator.

The 10 families that participated on the evaluation presented an intriguing pattern in the collision avoidance with $90 \%$ collisions occurred without the HUD whilst there was no collision with the use of the HUD as presented below.

Evidently the number of collisions accumulated per family indicates the number of major distractions occurred to the driver/parent which was unable to perform any collision avoidance manoeuvre, or brake abruptly on a timely manner.

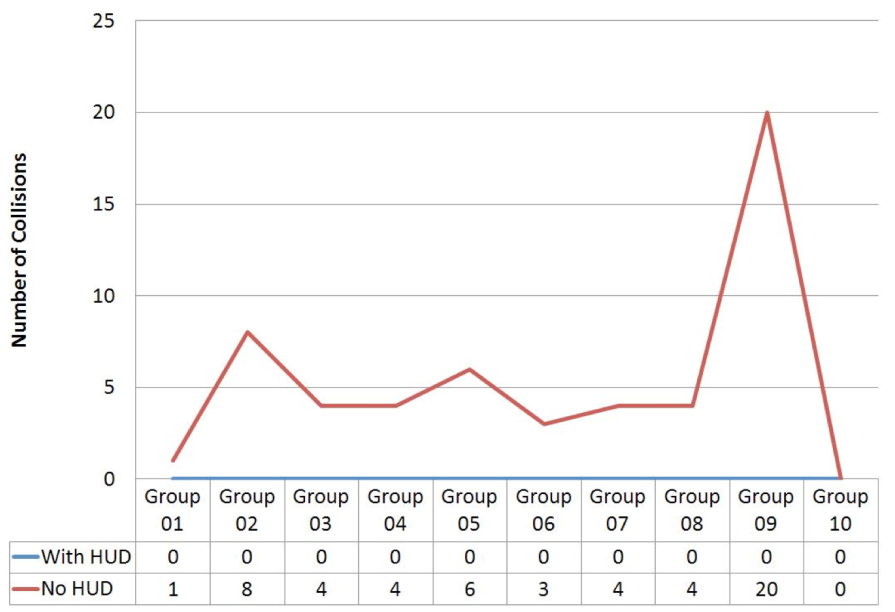

Fig. 7. Number of collisions recorded with and without the HUD interface.

The majority of the collisions appeared on motorway high-speeds (50-70mph), indicating potentially life-threatening outcome for the vehicle occupants. Notably only one driver/parent (family 10) managed to avoid the imminent collisions successfully both with and without the HUD interface.

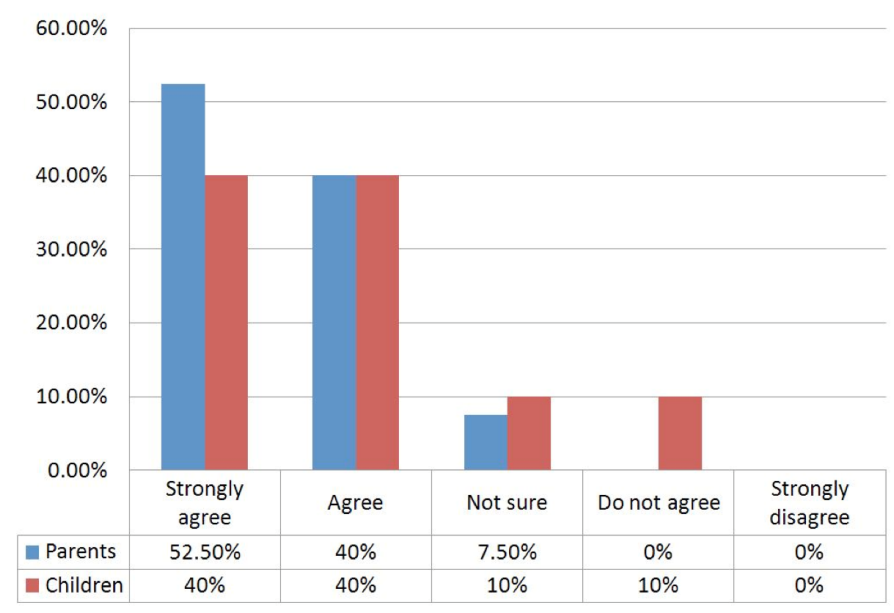

Fig. 8. Would you recommend this system to friends/family?
Finally, the analysis of the system acceptance by the users revealed that a $92,5 \%$ of the parents and $80 \%$ of the children would recommend this system to friends and family.

\section{CONCLUSIONS}

This paper presented the design and implementation challenges of our vehicular HUD interface designed explicitly to provide infotainment to the rear-seat passengers. The system entails a plethora of embedded applications aiming to attract the passengers' attention and consequently reduce driver's distraction. The latter has been proven a major issue particularly in long distance travelling with children.

The evaluation of the HUD system utilised a VR full-scale driving simulator that challenged the drivers to avoid imminent collisions whilst distracted by the rear-seated younger passengers. Additionally, a second evaluation was performed to identify the systems usability and technology acceptance from parents and children alike. Both evaluations provided an indicative appraisal of the system benefits and encouraging performance results of the drivers whilst using the proposed system.

Out future of work aims to improve further the interface based on the latest subjective feedback and enrich the context and interaction options for the different users. Furthermore, we envisage continuing the user evaluations experiments in order to recruit more users and obtain more statistically significant results.

\section{ACKNOWLEDGMENT}

The authors would like to acknowledge the contribution of Dr Warren Chan and Dr Soheeb Khan in the development of the Virtual Reality Driving Simulator. Also, the authors would like to acknowledge Dr. David Moore for his suggestions and overall support during the evaluation process.

\section{REFERENCES}

[1] J. Barker, "Driven to Distraction: Children's Experiences of Car Travel", Brunel University, UK, DOI 10.1080/17450100802657962, 2009.

[2] S.Wang, V.Charissis, and D.Harrison, "Augmented Reality Prototype HUD for Passenger Infotainment in a Vehicular Environment", in Advances in Science, Technology and Engineering Systems Journal, Vol. 2, No. 3, 634-641 2017.

[3] S.Wang, V.Charissis, J. Campbell, W.Chan, D. Moore and D.Harrison, "An investigation into the use of virtual reality technology for passenger infotainment in a vehicular environment, in International Conference on Advanced Materials for Science and Engineering (IEEE - ICAMSE), pp 404 - 407, DOI: 10.1109/ICAMSE.2016.7840359, Beijing, China, 2016.

[4] H. Okumura, T. Sasaki, A. Hotta, and K. Shinohara, "Monocular hyperrealistic virtual and augmented reality display" 2014 IEEE Fourth International Conference on Consumer Electronics (ICCE-Berlin), Berlin, Germany, pp.19-23, 2014 
[5] H. Okumura \& K. Shinohara, "Human Attention and fatigue for AR Head-Up Displays" 2016 IEEE International Symposium on Mixed and Augmented Reality (ISMAR-Adjunct), Merida, Mexico, pp. 306-309, 2016.

[6] V. Charissis, W. Chan, S. Khan, R. Lagoo, "Improving Human Responses with the use of prototype HUD interface", ACM SIGGRAPH Asia 2015, Kobe, Japan, 2015.

[7] V. Charissis, S. Papanastasiou, W. Chan, and E. Peytchev, "Evolution of a full-windshield HUD designed for current VANET communication standards", IEEE Intelligent Transportation Systems International Conference (IEEE ITS), The Hague, Netherlands, pp. 1637-1643, DOI: 10.1109/ITSC.2013.6728464, 2013.

[8] V. Charissis, and S. Papanastasiou, S.,"Human-Machine Collaboration Through Vehicle Head-Up Display Interface", in International Journal of Cognition, Technology and Work, P. C. Cacciabue and E. Hollangel (eds.) Springer London Ltd Volume 12, Number 1, pp 41-50, DOI: 10.1007/s10111-008-0117, 2010.

[9] G. Hoffman, A. Gal-Oz, S. David, and O. Zuckerman, In-car Game Design for Children: Child vs. Parent Perspective, IDC, ACM, New York, NY, USA, pp. 112-119. 2013.
[10] L. Brunnberg, O. Juhlin, and A. Gustafsson, "Games for passengers-Accounting for motion in location-based applications", ICFDG 2009, April 26-30, 2009, Orlando, FL, USA, ACM 978-1-60558-437-9, 2009.

[11] N. Broy, S. Goebl, M. Hauder, M, A, "Cooperative In-Car Game for Heterogeneous Players" Automotive UI 2011, Nov. 30th-Dec.2nd 2011, Salzburg, Austria, Copyright 2011 ACM 978-1-4503-1231-8/11/11, 2011.

[12] M. Nielsen, T. B. Moeslund, M. Storring and E. Granum, "HCI Beyond the GUI, Design for Haptic, Speech, Olfactory, and Other Non-traditional Interfaces", Kortum, P., (Ed), Elsevier, Morgan Kaufmann Publishers, pp.75-103, 2008.

[13] J. L. Gabbard, M. G. Fitch, K. Hyungil, "Behind the Glass: Driver Challenges and Opportunities for AR Automotive Applications", Proceedings of the IEEE, Vol. 102:2, pp.124-136, DOI: 10.1109/JPROC.2013.2294642, 2014.

[14] G. Underwood, D. Crundall, and P. Chapman, "Driving simulator validation with hazard perception", Transportation Research Part F: Traffic Psychology and Behaviour, vol. 14, no. 6, pp. 435 - 446, Special Issue: Driving Simulation in Traffic Psychology, 2011. 